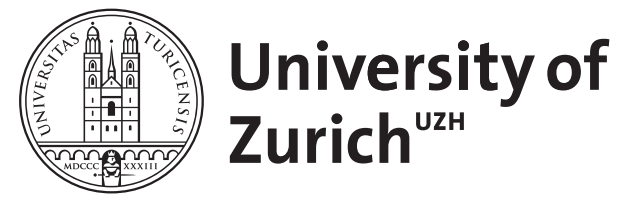
Archive

University of Zurich

University Library

Strickhofstrasse 39

CH-8057 Zurich

www.zora.uzh.ch

Year: 2009

\title{
Explicable explainers: The problem of mental dispositions in Spinoza's Ethics
}

Renz, Ursula

DOI: https://doi.org/10.1515/9783110211825.79

Posted at the Zurich Open Repository and Archive, University of Zurich ZORA URL: https://doi.org/10.5167/uzh-30952

Book Section

Published Version

Originally published at:

Renz, Ursula (2009). Explicable explainers: The problem of mental dispositions in Spinoza's Ethics. In: Damschen, Gregor; Schnepf, Robert; Stüber, Karsten. Debating Dispositions. Berlin: Walter de Gruyter, 79-98.

DOI: https://doi.org/10.1515/9783110211825.79 


\title{
Explicable Explainers: the Problem of Mental Dispositions in Spinoza's Ethics
}

\author{
URSULA RENZ
}

\section{Introduction}

Spinoza is often considered to be the Megarian among the early modern philosophers: The ontological arsenal of his metaphysics, so it is widely believed, is reduced to one singular entity, whose being is mere and eternal actuality, whereas singular things, timely events, and dispositional properties are regarded as being merely illusory. ${ }^{1}$ This view, it is further assumed, undermines our common sense view of mental dispositions. We usually think of ourselves as entities that are endowed with certain non-actualized mental properties like, for example, the ability to find the solution to mathematical problems or the inclination to get angry when someone disturbs us at work. And we often conceive of these traits as full-blown properties, which are just as real as our actual properties such as the property of my being female. But according to the standard conception of Spinoza's so called necessitarianism this cannot be the case. For necessitarianism unlike determinism not only rejects the idea of free will, but precludes the idea of individual subjects who are endowed with non-actualized mental capacities.

In this paper, I would like to challenge this view. Spinoza's metaphysics of modality is more moderate, and less absurd, than the Megarian picture that many textbooks depict. As I see it, Spinoza's intention is not to deny the reality of particular things nor their dispositional properties, but to show that they are conditioned entities that are completely explicable in terms of their properties and of the modifications they have undergone Understood in this manner, his approach is a suitable example of what I would call 'the third way' in the philosophy of dispositions. He neither endorses an empiricist or semantic reductionism, nor is he a metaphysical realist, who considers dispo-

1 This view was put forward in the Enlightenment by early modern philosophers who maintained in some respects similar views, but wanted to disassociate themselves from the Dutch heretics, that is, in particular Nicolas Malebranche and Gottfried Wilhelm Leibniz For the Aristotelian Critique of the Megarian view of dispositional properties as well as for a defense of our common sense view, cf Jansen in this volume 
sitions as fundamental forces or irreducible properties of things. ${ }^{2}$ In contrast to these well known accounts, Spinoza's approach is more appropriately characterized as a combination of a version of radical rationalism and some kind of common sense realism. He assumes that every thing, event, or state can be explained in terms of its actual properties and its actual causal relations. Yet this is not equivalent to saying that dispositional properties do not really exist or, that it is pointless to refer to them. For Spinoza, dispositional properties have an important explanatory function in our account of certain phenomena, even though they can be further analyzed.

This approach to dispositional properties is of particular interest in regard to mental capacities. Spinoza's philosophy of mind is best understood as following from his rejection of the conceptual framework underlying the Cartesian conception of mind. As explicitly stated in the correspondence with Hobbes on the Meditationes, Descartes maintains that the existence of the human mind as a substance cannot be directly known, but it can be only indirectly inferred, that is, only insofar as it is conceived of as the ontological substratum of our mental acts, faculties and properties. ${ }^{3}$ The assumption that the mind is endowed with specific faculties in turn suggests that there is some part of human mental behavior that cannot be completely explained in terms of its actual mental features. Spinoza in contrast conceives of the human mind in a manner that denies the admission of such an unintelligible rest. Neither is the mind itself a substratum bebind or bearer of mental acts and properties, nor are there any specific faculties it is endowed with. Unlike Descartes, whose rationalist claims in regard to physical objects are quite radical, while being quite restricted in his view of the human mind, Spinoza assumes that both, mental and bodily entities, are completely intelligible.

In the first section of this paper, I will expound this approach in more detail. I will give a short sketch of Spinoza's theory of modality and explicate the explanatory function of dispositional concepts in the Ethics. I will show that they are useful only in specific contexts; when we want to account for the existence and the actions of those things that are not determined by their own essence to be or to act in a certain way. I maintain that they explain why those things, which are not determined by their essence to do or not to do certain things, behave the way they do. Finally, I will show how Spinoza's so called necessitarianism reduces to his rationalist conviction that all there is, including contingent particulars and possibilities, can, in principle, be completely conceived of in terms of necessary causal connections (section 1).

The other three sections of the paper are concerned with the problem of mental dispositions in the Ethics. It is a remarkable feature of Spinoza's philoso-

2 Cf also Schrenk and Mumford in this volume

3 Cf AT VII, 176 
phy of mind that he rejects the idea that the mind is essentially endowed with mental faculties that are ontologically distinct from its actions. This is a fundamental challenge to our ordinary concept of the human mind. What is the human mind, so one might ask, if one cannot understand it as some kind of substance endowed with certain faculties prompting a certain type of mental output? Before addressing the question of the ascription of particular mental capacities, I would, therefore, like to discuss the implications of Spinoza's concept of the human mind (section 2).

The third section is concerned with Spinoza's concept of idea. Due to the historical influence empiricist approaches had in contemporary philosophy of mind, we often tend to think of ideas in terms of episodic representational mental states. This, however, does not correspond to the way Spinoza makes use of this term. In the Ethics, ideas certainly are considered to be the basic units of the mental. Unlike Lockean ideas, however, these basic units are not merely individuated by their representational content, but also by their inferential relations to other mental states or ideas. This conception has enormous implications: It suggests that in the Ethics the term 'idea' refers at least sometimes to a disposition to think of particular things in a certain way and not to our actual mental state. Therefore, given this understanding of 'idea', we do indeed have mental dispositions according to Spinoza. They are nothing unreal or illusory. They do however not consist in some ultimate and undetermined faculty such as a free will, but in the ideas connected by association or inference with other ideas we actually have (section 3).

In the fourth section, I will discuss the passage of the Ethics where Spinoza most explicitly makes use of a dispositional concept, namely the Scholium of 2p13: He says that minds are to the same extend capable, 'aptus', of perceiving many things at once as the corresponding bodies are capable of doing many things at once. I will argue that Spinoza thereby establishes a conceptual device that allows him to make sense of central intuitions that we usually rely on in trying to understand the experiences of other persons or other organisms. Once again, we encounter the combination that I have described above as radical rationalism mixed with common sense realism (section 4).

\section{A Type of Transcendental Philosophy: Interpreting Spinoza's Theory of Modality}

The intention to understand a phenomenon is often driven by the following expectation: We assume that the object in question (a particular event, the quality of an experience, or the disposition to act in a certain way) can in principle be explained in terms of its properties and of the modifications to 
which it has been subjected and which, taken together, completely describe it. If we had a complete description of an object, we could, therefore, derive necessarily true statements about its properties including existence or occurrence at a given moment. If we lack a complete description however, we are required to look for further explanations.

It is the intuition that our demand for knowledge is fully satisfied only by a complete explanatory description of the object that motivates Spinoza's metaphysics and, in particular, his theory of modality. He thereby endorses a very strong notion of what it is to fully know or understand something. We fully know a thing, if and only if we grasp what necessitated it.

In contemporary analytic Spinoza scholarship, this quest for explanatory completeness is often identified with a metaphysical necessitarianism. Spinoza is claimed to establish a modal metaphysics that denies the reality of any possibilia. Don Garrett for instance ascribes the view to Spinoza that "every actual state of affairs is logically or metaphysically necessary, so that the world could not have been in any way different than it is." "Such a necessitarian view of modality contradicts the common sense belief that things can have dispositions to act in a certain manner. If all things in the universe are metaphysically necessary, conceptually it does not seem to make sense to assume that dispositional properties exist. ${ }^{5}$

I think however that this necessitarian reconstruction of Spinoza's metaphysics is rather shortsighted. It is true that in many places Spinoza denies the existence of mere possible things. So he says, for instance, in 1p29:

In nature there is nothing contingent, but all things have been determined from the necessity of the divine nature to exist and produce an effect in a certain way. ${ }^{6}$

And in 1p33, he asserts:

Things could have been produced by God in no other way, and in no other order than they have been produced. ${ }^{7}$

$4 \quad$ Garrett 1991, 191f

5 At this point, I would like to address a distinction made by Ludger Jansen in his discussion of Aristotle's theory of dispositions (in this volume) According to Aristotle, dispositions are not merely possibilities that one had to spell out in terms of sentence operators, but some kind of predicate qualifiers I think this is a convincing and fair description of our common sense intuitions In a necessitarian approach, however, this distinction is challenged The claim that every thing can be completely described implies that every property, which a thing has, can be explicated in terms of necessary and, hence, unqualified predicates The sentence that Ludger Jansen has the non-actualized ability to speak Chinese is therefore not a wrong, but an incomplete description of the actual state of Ludger Jansen's mind

$6 \quad 1 \mathrm{p} 29$, cf for the citation: Spinoza, Collected Works, ed Curley, 433 In the following all English citations are taken without change from Curley's translation

$7 \quad 1$ p33, Collected Works, 436 
According to these two propositions, Spinoza seems to put forward a radical necessitarianism that precludes the existence of unrealized entities and, hence, also dispositional properties.

This interpretation is further supported by Spinoza's theological position motivating the above claims. There is considerable evidence that he developed his views on modality in full awareness of its theological implications. As his letter to Oldenburg from February 1676 reveals, he was willing to affirm all the dangerous claims, which follow from the necessity of God and which Oldenburg advised him to withdraw. ${ }^{8}$ He knew that the assumption of divine necessity ruled out the traditional notion of God's personhood as well as of divine teleology, and he, of course, also knew that identifying God's necessity with the necessity of being undermines the idea of free will. ${ }^{9}$ As far as theology is concerned, he obviously was willing to embrace necessitarianism.

The picture, however, changes when it comes to the explanation of the existence and actions of particulars. ${ }^{10}$ Unlike the divine substance, whose existence and properties follow from its essence, particular things are determined to exist and to act by other particulars. In $1 \mathrm{p} 28$ Spinoza claims:

Every singular thing, or any thing which is finite and has a determinate existence, can neither exist nor be determined to produce an effect [operari] by another cause, which is also finite and has a determinate existence; and again, this cause also can neither exist nor be determined to produce an effect unless it is determined to exist and to produce an effect by another, which also is finite and has a determinate existence, and so on, to infinity. ${ }^{11}$

He obviously thinks that particulars, too, are subject to necessary determination, otherwise he could not rule out unconditioned existence or action. In contrast to the above cited claims however, the necessity involved in this case is not defined in terms of God's necessary creation, but in terms of some necessary antecedent and the infinite causal chain of particular things. Moreover, it has to be emphasized that he does not deny that, given different antecedents, things could have turned out differently.

This suggests that Spinoza's claims on modality are motivated by the epistemological intuitions sketched above, rather than by some metaphysical ideas concerning the reality or non-reality of things. Spinoza's necessitarianism, as I see it, is not a type of descriptive metaphysics delineating which things exist and which do not. Instead it is better understood as a version of transcendental argument that analyzes the necessary presuppositions of a radical rational-

8 Cf Letter 78 In: Spinoza Opera, vol 4 (=G IV), 326f

9 For the theological background cf Carriero 1991 and Perler 2006

10 It has to be mentioned that Spinoza does not regard God as a particular thing, as particulars are merely affections or modifications of God's attribute Cf also 1p25c, Collected Works, 431

11 1p28, Collected Works, 432 
ism. I shall not discuss here whether or not this weakens Spinoza's necessitarianism. ${ }^{12}$ But I think we can, without going into further discussion, ascribe to Spinoza the following claim: Even if necessitarianism is true, it does not help us in explaining either the existence or the action of any particulars. If, however, we accept this claim, we cannot directly appeal to metaphysical necessity in order to explain the behaviour of a particular thing. Instead, we have to seek a causal analysis of its concrete determination. Considered in this way, Spinoza does not maintain that we can deduce a complete description of things from the conceptual claims grounding his metaphysics.

In this context, a comparison of Spinoza with Leibniz might be helpful: Leibniz, in some tension with (if not to say in contradiction to) the metaphysical premises of his concept of complete notions, ${ }^{13}$ rejects necessitarianism for theological reasons. Just as in Leibniz, Spinoza's views on God's freedom and on the particulars belong to different and separate domains of philosophical concerns, i.e. theology on the one hand, ontology on the other. In contrast to Leibniz, however, Spinoza combines a necessitarian picture of God - ruling out traditional theology - with a determinist view about the ontology of particulars that makes sure that complete explicability holds.

In light of our discussion of Spinoza's modal metaphysics so far, the following claims seem to hold true in the Spinozistic framework in regard to dispositional properties:

(1) Contrary to what one might assume at first glance, there is conceptual space for dispositional properties in Spinoza's modal metaphysics. The ascription of dispositional predicates is not pointless, although they have a restricted scope. It makes no sense to ascribe dispositional properties to God (including the capacity to create or not to create certain particular things), but we can reasonably argue about dispositions of particular things.

(2) Due to the necessity of causal determination, and provided that causal influences are always actual, the ascription of a dispositional concepts has however only some kind of provisional epistemic legitimacy. Dispositions can in principle be explained in terms of the actual properties of its bearer, or in terms of things affecting its bearer. That someone is inclined to do $\mathrm{x}$ rather than $y$ has thus nothing to do with an original power, but with her being the focal point of several (internal and external, direct and indirect) causal relations, which together amount to a certain disposition to do x. As humans we

12 In order to answer this question, we would have to determine how the two necessities involved, the divine necessity and, the case of necessary causal determination of particulars, are conceptually related This cannot be done without at the same time defending a particular interpretation of other issues in Spinoza's metaphysics For further discussion cf Schütt 1985, Garrett 1991, and Curley/Walski 1991

13 Complete notions include not only the hypothetical conditions, but also the knowledge when they are given I would like to thank Robert Schnepf for a very helpful discussion on this issue 
can, however, never eliminate all of our dispositional concepts, nor can we reasonably deny the reality of the dispositional properties denominated by them. Certainly, if we could account for the whole sum of all actual causal influences on an object, we could dismiss dispositional concepts. But as human beings, we (almost) never arrive at this point. Meanwhile our common sense language as well as many provisional scientific explanations make use of dispositional concepts and reasonably assume that they refer to some real causal interaction between real things. Dispositional concepts are thus best characterized as some kind of explicable explainers. They help us to conceive of the properties of things in a provisional common-sense-like manner, when we lack a complete causal analysis.

(3) This points to another, rather meta-theoretic consequence of Spinoza's modal metaphysics. The restricted scope and the provisional epistemic legitimacy of dispositional concepts lead to an important shift in conceiving of the main focus of a philosophical investigation of dispositional terms. What philosophy primarily has to discuss is not whether or not dispositional properties really exist. The interesting question is rather how we should conceive of them in order to account for the explanatory function they perform in science. Philosophy has to provide the conceptual framework that facilitates the rational use of dispositional terms while it insists on further explanation of the dispositional properties that they denote.

These three points have an enormous impact on Spinoza's philosophy of mind. Being a particular, the human mind belongs to those entities to which dispositional properties can be ascribed. The question arises: What kind of causal influence lies behind our mental dispositions? Another important issue is how certain specific mental capacities are to be conceived of in order to be subject to further analysis. Before addressing these two problems in detail, some general assumptions underlying Spinoza's concept of the human mind need to be exposed.

\section{Re-categorizing Human Thought: Spinoza's Deflationary Concept of Mind}

Spinoza's general approach to the mental is probably best characterized by a close analysis of his first definition of the human mind. ${ }^{14}$ It says:

14 The Ethics provides two definitions, one in 2p11 and another in 2p13 (both cited in the main text) Even though the second one appears to be merely a more precise version of the first, they address slightly different problems The first determines what minds consist in, the second answers the question of what individuates particular minds This difference has always been neglected in Spinoza scholarship For a detailed discussion cf also Renz 2006 
The first thing that constitutes the actual being of a human Mind is nothing but the idea of a singular thing which actually exists. ${ }^{15}$

At first glance, this definition sounds rather odd. Usually, we would expect the human mind to have ideas, and not to consist of or to be an idea. A closer look at the following passages, however, leaves no doubt, that Spinoza really wanted to say that the mind is an idea. Since already on the next page, he gives a second definition of the human mind where he states more precisely:

The object of the idea constituting the human Mind is the Body, or a certain mode of Extension which actually exists, and nothing else. ${ }^{16}$

Why does Spinoza claim that the mind is an idea, instead of merely pointing to the fact that he has ideas? What motivates this move? And what insights does it provide? In order to answer these questions, we have to pay attention to the following two points:

(1) The quoted passage relies on an ontological assumption about humanity in general. The essence of man is to be conceived of in terms of modes, and not in terms of substance or of substantial form, as has been common in the philosophical tradition before Spinoza. ${ }^{17}$ Accordingly, neither the existence, nor the actions, or passions of a person can be understood with the help of the concept of his essence. If we want to explain one of these properties, we have to refer to the causal interactions of a person with other particular things.

These insights also apply, of course, to the human mind. Our mental life has also to be accounted for in terms of an analysis of the causal interactions between several mental states, or in Spinoza's terminology: ideas; and not by reference to the essence of the human mind. When we want to explain why someone has a certain idea, we have to examine how this idea is caused by another mental state. I will address the question of what it means that an idea is caused by another idea later on. Here it is only to be emphasized that, by conceiving of the mind as a particular idea, Spinoza satisfies first of all the demand underlying the ontological assumption that man consists of modes. If all explanations of mental states is based on causal interactions among different ideas, and if the mind has to be understood as a cause of our mental states, then the mind itself must be conceived of as an idea.

(2) The claim that the mind is a particular idea undermines one of the implicit tenets of our ordinary concept of the human mind, namely the assumption that it is the bearer of mental states or properties, which in turn presupposes a categorical distinction between the ontological status of the

\footnotetext{
2p11, Collected Works, 456 2p13, Collected Works, 457

17 Cf 2p10 and 2p10c, Collected Works, 454 As has been emphasized by Gueroult 1974, 111, this denial is directed at the same time against Aristotelianism as well as against Cartesianism
} 
mind and the mental. By defining the mind as an idea, Spinoza rejects the notion of the human mind as some kind of bearer. One can assume that this is an essential part of his program. Spinoza wants to get rid of one of the basic conceptual constraints grounding many approaches in the philosophy of mind. By maintaining that the human mind is nothing but a particular idea, he flatly refuses to consider minds as some kind of unintelligible substrata of mental states. Instead, the mind is conceived of as belonging to the same ontological category as our other ideas. It thus cannot be a principle beside, bebind, or beyond our actual mental life. And this, in turn, implies a radical denial of any essential mental faculty. ${ }^{18}$

Although puzzling at first glance, Spinoza's claim that the human mind is or consists of a particular idea makes quite a lot of sense. It presents a fundamental critique of any concept of the human mind that presupposes a categorical distinction between the mind and the mental. In a way, his critique resembles the one put forward by Gilbert Ryle in The Concept of Mind against the Cartesian model of the mental. ${ }^{19}$ Like Ryle, Spinoza attacks the conceptual framework of Cartesianism and seeks to undermine the widespread belief that the human mind is something bebind the mental. But unlike Ryle's, Spinoza's approach is not based on an analysis of language, nor is it driven by an empiricist conception of causality according to which the causal relations are nothing but the regular association between events or properties. Instead, his arguments rely on the rationalist assumption that the mental life of a person, though we often lack knowledge of it, could in principle be exhaustingly analyzed in terms of the ideas he has.

Given this rather deflationary approach to the human mind, one might ask how Spinoza can account for our phenomenological intuition that we ourselves are epistemic subjects, who have ideas or mental states? I will answer this question in the next section. It is, however, worth to emphasize the following two points:

(1) A closer analysis of the argument by which Spinoza demonstrates that the human mind consists of a particular idea shows that he does not preclude the intuition that we can have ideas or mental states, nor does he deny that some ideas can be prior to others. On the contrary, he claims that the idea which is the human mind must in some sense be prior to the mental states we have. ${ }^{20}$ Spinoza does not want to deny all the distinctions we usually make when reflecting on our mental states. His goal is rather to suggest a conceptual framework that does not arbitrarily end the theoretical analysis of

18 Cf also Bartuschat 1992, 96 and 101, and Yoshida 2004, $63 \mathrm{f}$

19 Cf Ryle 1949, 16ff I will not discuss here whether or not Ryle's exposition of the Cartesian myth provides a fair analysis of Descartes' own approach

20 Cf the first of the two references to $2 \mathrm{ax} 3$ in 2p11dem; Collected Works, 456 
the mental at a certain point. Thus, Spinoza does not think that anything is fundamentally wrong with our phenomenological intuitions, but he does question whether sceptical conclusions should be drawn from them. There is no unintelligible rest in conscious experience according to Spinoza. It is for this reason that he puts forward a concept of the human mind that is completely different from the one maintained either by the Aristotelian or Cartesian approaches to the mind. Instead of considering the mind as a substance, or as a part of a substance that has the faculty to have or to produce ideas, he suggests that we should conceive of it in terms of the same ontological category as the mental, that is, in terms of a mode of thought or of a particular idea.

(2) The claim that the human mind is a particular idea only gives a provisional definition of the human mind, as it does not yet provide a criterion to distinguish it from other ideas, nor does it show how single minds are individuated. As the second of the two claims quoted above suggests (2p13), Spinoza considers only those ideas that are about ourselves, insofar as we are a certain body, to be human minds. Consequently, the idea that constitutes the human mind involves necessarily some kind of basic self-awareness. ${ }^{21}$ Spinoza asserts that thought and extension are generally conceived of as distinct features of one and the same thing, and that mental and bodily items of particular things are only conceptually distinct, and not ontologically different things. 22 We can assume that the idea, which constitutes our mind, is about some aspect of ourselves, that is, of ourselves insofar as we are bodily things. The mind is thus distinguished from other ideas by the fact that it consists in some kind of self-awareness. One can, of course, speculate whether or not stones have such knowledge according to Spinoza. ${ }^{23}$ Yet it is at least obvious that our ideas of stones are not items of self-awareness, and that they are not minds.

It thus follows that the concept of the human mind suggested in the Ethics, though deflationary in its general approach, does not reject the intuition that we, insofar as we are thinking things, can have ideas. Spinoza does not deny the assumption that humans have the mental capacity to have ideas, he only suggests a different theoretical framework for thinking about it.

Up to now, I have not discussed precisely what ideas are. They are sometimes described as 'mental states', and I have used this notion occasionally in this section. But, in some way, this expression is problematic. Not only is the term 'mental state' often used as a dummy term, which does not explicate

21 I argued for this in more depth in Renz 2006 and Renz 2009

22 Cf for these claims $2 \mathrm{p} 7 \mathrm{~s}$, where Spinoza's so called identity theory is defended Collected Works, $451 \mathrm{f}$

23 Spinoza himself does so in a hypothetic manner in a letter to Schuller However, he never does assert that stones have a mind or consciousness Cf also G IV, 266 
what it means to be in a mental state, it also tacitly presupposes that mental states are primarily occurring entities. Spinoza however does not understand the mental in this manner as a closer analysis of some of his psychological claims will show: Not only are our actual and conscious thoughts conceived of as ideas, but also our unconscious mental states, that are connected by associative or inferential relations to our conscious ideas. In the following section therefore, I would like to discuss in more detail how Spinoza understands the concept of ideas and how he uses it to address the problem of mental capacities.

\section{Explaining Dispositions in Terms of Content: Spinoza's Concept of Idea and Mental Causation}

In order to understand Spinoza's notion of idea, one has to draw attention to the following three points:

(1) Ideas are mental and not bodily items. Spinoza emphasizes this in his definition of the term 'idea,' where he maintains that ideas are concepts "of the Mind that the Mind forms because it is a thinking thing." 24 This shows that, in some respects, his position is closer to Descartes' substance dualism than one might think. Although he does assume that mind and body express one and the same thing, and hence belong to one and the same reality, he does not ascribe ideas to bodies or reduce them to bodily states. On the contrary, although the mind and the body of a person also refer to one and the same thing, they are conceptually distinct, and to neglect their conceptual difference is no less problematic than to ignore their ontological identity. ${ }^{25}$

(2) Ideas always involve an implicit knowledge claim, or in Spinoza's words: an affirmation. ${ }^{26}$ This assertion is best clarified with the help of a short

24 2def3, Collected Works, 447 Here Spinoza opposes Hobbes' critique of Descartes according to which thoughts, although they are mental, are to be ascribed to the body cf AT VII, 172f For the impact the Objections against the Meditations in general had on Spinoza, cf also Rousset 1992

25 For a further discussion of the implications of conceptual cf also Della Rocca 1996 Della Rocca showed that the physical and the mental constitute two opaque semantic contexts

26 Curley 1969, 123-127, suggested a logical reading of Spinoza's concept of ideas This has been criticized by Wilson 1999, 153, and Della Rocca 1996, 8, who put forward psychological interpretations I think that the logical and the psychological interpretations are not necessarily alternatives to each other Ideas are ascribed in the Ethics to minds just as today we ascribe mental states to mind, the term 'idea' hence applies to psychological entities The content of particular ideas, on the other hand, is to a large degree determined by inferential relations to other ideas, which suggests that they are logical entities Taking these points together one can say that Spinoza's approach is similar to the one put forward by Wilfrid Sellars in Empiricism and the Pbilosophy of Mind. 
examination of his discussion of the problem of free will. Just as in the case of the concept of mind, Spinoza's first step is to deny the existence of something bebind our volitions. ${ }^{27}$ There is no faculty by means of which we either will or will not do something. One might however object that this denial makes any volition unintelligible, for how can we exert particular volitions if no faculty of willing is activated? Spinoza responds to this objection by arguing that all ideas involve some kind of affirmation. ${ }^{28} \mathrm{He}$ illustrates this claim with the same example Descartes uses to defend his notion of innate ideas: Given that we have the geometrical concept of a triangle, we know and affirm by the very same concept that its three angles equal $180^{\circ} .29$ The necessary connection between the conceptual knowledge of a thing and the propositional knowledge of its having certain properties functions in this manner as the model for Spinoza's concept of affirmation. In contrast to Descartes, for whom only innate ideas necessarily involve the affirmation of some proposition, for Spinoza, it characterizes all of our ideas, including obscure and inadequate ones. This in turn sheds some light on the underlying psychology of the process of affirmation. According to Descartes we can withdraw from our affirmation of ideas, for it is a voluntary act. Not so in Spinoza. For him, the affirmation of an idea is required by its particular content. Accordingly, the will of a person is merely a function of the content of the ideas he has. If he has the idea of $x$ and if this idea bears a relation to the idea of $y$, he necessarily will affirm the idea of $y$ whenever he thinks of $\mathrm{x}$.

(3) In the introduction, I said that the term 'idea' is used in the Ethics to refer to the basic mental units. It would however be wrong to take ideas as some kind of psychological atoms. On the contrary, they are always and necessarily related to other ideas by different kinds of connections, inferential as well as associative ones, and they can never be isolated from those connections. Conceiving of ideas in this manner has enormous implications for the question of the determination of mental content as well as for the problem of epistemic justification. The relation of an idea to other ideas determines at least in part what particular content it has, and it has to be assumed, therefore,

27 2p48: In the mind there is no absolute, or free, will, but the Mind is determined to will this or that by a cause which is also determined by another, and this again by another, and so to infinity. Spinoza generalizes this point in 2p48s: In this same way it is also demonstrated that there is in the Mind no absolute faculty of understanding, desiring, loving etc. From this it follows that these and similar faculties are either complete fictions or nothing but Metaphysical beings, or universals, which we are used to forming from particulars. So intellect and will are to this or that idea, or to this or that volition as 'stone-ness' is to this or that stone, or man to Peter or Paul. Collected Works, 483

28 2p49: In the Mind there is no volition, or affirmation and negation, except that which the idea involves insofar as it is an idea. Collected Works, 484

29 2p49dem, Collected Works 484 Descartes uses this example in the fifth meditation, cf AT VII, 68 
that Spinoza asserts some kind of ideational holism. ${ }^{30}$ Moreover, as every idea involves some knowledge claim, he also maintains an epistemic coherentism. Although Spinoza assumes that the truth of an idea ultimately consists of its complete correspondence with the object, ${ }^{31}$ he nevertheless asserts that the adequacy of an idea, that is, the knowledge it provides us, does not depend on its relation to the represented object, but on its relation to all other ideas. ${ }^{32}$

One might wonder whether all of these beliefs form a coherent whole. Let me remind you that the principal goal of Spinoza's metaphysics was to ensure complete intelligibility of being. One can argue that complete intelligibility can be maintained if and only if, one singular concept of reality is affirmed and ideally represented by one singular true idea. This idea does not only correspond to reality, but also involves a whole coherent system of ideas by means of which we can adequately think of all particular that there are. It is, I claim, this intuition that stands behind Spinoza's notion of the 'idea of God', and not the assumption of some divine self-consciousness which continuously generates our minds and its mental states, as it sometimes suggested in pantheistic readings. ${ }^{33}$

Instead, the question arises how Spinoza's notion of idea contributes to the explanation of mental dispositions. One has to distinguish between two different layers of the problem. On a general level, we must clarify what it means, in a Spinozistic framework, that the human mind, which itself is an idea, has other ideas. The intuition that human beings are capable of having mental dispositions is to be accounted for within Spinoza's framework by explicating the relation between the idea constituting a mind and the ideas it has. On a more specific level, explanations are also required for certain characteristic mental dispositions that we ascribe to particular persons, for example, when we say someone is irascible. How can Spinoza account for these kinds of properties? In other words: How can he explain that someone behaves, under certain condition, rather in this than in that way?

Concerning the first question, we can say that if there is an idea constituting a mind, it provides us at the same time with other ideas. For every single idea is necessarily connected with other ideas, and, given that ideas involve affirmations, in having one idea we at the same time have many other ideas.

30 For Spinoza's holism, cf also Brandom 1976, and Della Rocca 1996

31 Cf 1ax6, Collected Works, 410

32 Cf 2def4, Collected Works Spinoza equates adequacy of ideas with the intrinsic denomination of their truth This has sometimes been taken as a psychological feature, so that adequacy corresponds to the certainty an idea involves The problem of this interpretation is that it suggests a psychological understanding of adequacy But this gives rise to serious problems, as I expound elsewhere, cf Renz 2009 Instead I take "intrinsic" to hint at the assumption, that by mere coherence with all our other ideas, a particular idea can be epistemologically justified

33 This view has been expounded and criticized by Wilson 1999, 126ff 
What accounts for the existence of our mental capacities is therefore the fact that our mind, conceived of as an idea, relates to other ideas we affirm, if not prevented by another, opposite idea.

I will not discuss this answer in depth. I would, however, like to emphasize one point: Whether this approach can satisfy us, or not, depends, among other things, on the answer to the following question: Who is the subject that has the idea constituting the human mind and who is thereby endowed with the disposition to affirm other ideas? God? Any other ideal observer? Or the person whose mind we are talking about?

As mentioned above, the idea which constitutes our mind is distinguished from other ideas that are not minds by the fact that it possesses some kind of self-awareness. It must therefore be the person herself, the subject who has the idea constituting her own mind. One can speculate that the subject is provided with other ideas due to the fact of her self-awareness. The mental capacity to have ideas depends on the existence of self-awareness. In a way, this comes strikingly close to the fundamental insight of Kant's transcendental deduction, though the latter is conceived of as a transcendental argument, which is not the case in Spinoza. Both, Kant and Spinoza, seem to hold that it is due to self-awareness that we can know other things as well.

The second question is even more important in this context: How can we account for the fact that persons have a tendency or an inclination to behave in a certain way rather than in another? As we have shown, Spinoza denies that the essence of man can be conceived in terms of substances or substantial forms, and therefore, as claimed above, our mental life also has to be explained by an analysis of the causal interaction between mental items. We however have not yet explained what it means for an idea to cause another idea. Knowing that Spinoza maintains some kind of ideational holism, we can presume that an idea is caused by another one if and only if, the content of the latter is partly determined by the content of the former. Understood in this manner, the question of causation of ideas is not concerned with the generation of mental states, but with those semantic processes that determine the contents of our thought. To cause an idea is not to bring it into existence via a psychological process, but to determine its particular content.

But how can this notion of mental causation help to explain why someone behaves in this way rather than in that way? Well, this kind of mental causation works also in the case of the relation between a person's mind (which consists in a particular idea) and the ideas this person has. The content of the idea constituting his mind is one, though, not exclusively, the cause for what he is thinking or feeling in certain circumstances. If we take into consideration that ideas constituting minds are always concrete ideas that differ in extension as well as in intension, we can use this notion of mental causation as a conceptual model for the explanation of our own as well as of other people's 
mental dispositions. Let's for example assume that I perceive myself as a powerful personality. I will tend, in that case, to perceive other strong personalities as peers, whereas, if the idea constituting my mind represented me as a weak and fragile person, I will think of strong personalities as a threat to me.

This is of course a very rudimentary model, but not in itself inconsistent. Moreover, it shows why the acquisition of knowledge and the reflection on one's own behavior can, at least in principle, change one's mental dispositions. Since the mind is itself an idea and is not categorically distinct from the ideas we have, it is not only the case that the mind determines what we think, but what we think determines what mind we have. And this, of course, is no less plausible. Once I have learned that other individuals who I was inclined to perceive as heroes are no less dependent on other human beings than I am, and make mistakes just as I do, I will tend to perceive myself as stronger than before.

To summarize, we can say that Spinoza does not deny the reality of mental dispositions but he suggests a conceptual shift in our understanding of them. Instead of referring to general and irreducible faculties which, when activated, produce a wide range of effects, we have to focus on the more fine grained mental capacities involved in our ideas. The intention of this conceptual shift is clear: Ideas can be analyzed by their relations to other ideas, and in this manner mental dispositions become completely explicable.

One could object here that, even if we could in principle account for the mental capacities of a person in terms of the system of ideas he has, to look for a complete analysis of this system is a highly ambitious goal. It is indeed extremely improbable that we will ever acquire full knowledge of his mental dispositions. But what is worse: Spinoza's concept of idea cannot provide a criterion for the ascription of those provisional dispositional concepts we need as long as we lack a complete analysis. Such a criterion however, is, even for Spinoza's rather deflationary view, quite an important requirement, for we cannot get rid of all of our provisional dispositional concepts at one and the same time. The next section, therefore, will discuss the principle Spinoza introduces in order to account for the specific mental capacities of specific types of beings. I will show that this principle also provides a heuristic criterion for the rational ascription of provisional dispositional concepts.

\section{Conceptualizing Types of Mind: The Proportionate Correlation Between Mental and Physical Capacities}

It is one of the striking aspects of Spinoza's philosophy of mind that, once he has given his definition of the human mind, he interrupts his discussion with a short exposition of the basic principle of mechanistic physics and of his 
natural philosophy in general. But why do we need physical knowledge if the mental is conceptually distinguished from the body, so that not only causal interaction, but even explanatory reduction is precluded? ${ }^{34}$

Spinoza justifies this move by appealing to the idea of specific differences between human minds and the minds of other things. ${ }^{35}$ One might wonder whether this is consistent with the dismissal of the notion of essential mental faculties discussed above. We cannot, however, deny that minds differ enormously in what they can or cannot do. Even if we reject natural kinds, or categorical differences between types of minds, we must, from a commonsense point of view, be able to differentiate between certain types of minds. We must however not merely posit these differences, but they must be somehow accounted for. Spinoza therefore puts forward the idea of a correlation between an individual's mental and physical capacities:

I say this in general, that in proportion as a Body is more capable [aptius] than others of doing many things at once, or being acted on in many ways at once, so its Mind is more capable than others of perceiving many things at once. And in proportion as the actions of a body depend more on itself alone, and as other bodies concur with it less in acting, so its Mind is more capable of understanding distinctly. ${ }^{36}$

The question arises whether or not Spinoza thereby embraces some version of physicalism implying an explanatory reduction of mental capacities to physical capacities. I don't think that is the case, since he merely states proportionality between the amount of certain bodily and the amount of certain mental capacities. This, moreover, has to be seen in the light of $17^{\text {th }}$ century psychology. Spinoza hereby rejects one of the underlying ideas of Descartes' Passions de l'ame according to which the passions of the body are correlated with actions of the mind and vice versa. ${ }^{37}$ Whereas Descartes seems to assume some kind of inverse proportion, Spinoza maintains that the amount of certain capacities of a mind is proportionally the same as certain capacities of the body.

But how, one might wonder, does this assumption of proportionate correlation help to account for differences between types of minds, especially if it does not allow for a reduction to types of bodies? In order to answer this question, three points have to be observed:

(1) The assertion of a correlation between mental capacities and physical constitution is not inferred from empirical observation. Instead, it is implied by one of the central ontological claims of the Ethics asserting that there is a pervasive correspondence of the causal order of ideas with the causal order of

\footnotetext{
For a detailed analysis of this point cf Della Rocca 1996

Cf Collected Works, 458

Collected Works, 458

Cf AT XI, $327 \mathrm{f}$ and $354 \mathrm{f}$
} 
things. ${ }^{38}$ By assuming a correlation between mental and physical capacities of individuals, Spinoza hence relies on a conceptual constraint of his metaphysics that at the same time precludes any ontological reduction of one type of attribute to another. It does not, however, preclude the possibility that empirical knowledge provided by natural sciences can be used to account for dispositional properties. On the contrary, given this correlation and given certain mechanistic explanations of physical capacities we can, at least in principle, justify the ascription of mental capacities to certain types of things in this manner.

(2) The correlation holds universally, since it applies to all individuals. According to the single definition given in the physical excursus, a thing is an individual if and only if a certain number of particulars constitute either one moving thing or one homeostatic system in which a fixed proportion of motion and rest is maintained. ${ }^{39}$ In other words: An individual is a thing whose physical existence and actions can be explained in terms of the causal role of its parts. But this definition not only covers all bodies, and hence, all finite things, but it also applies to the universe, as far as it is conceived of in terms of the causal role of its parts. The assumed correlation between mental and bodily capacities can thus be used to analyze all kind of things and their ideas, though, as I will argue below, not all kinds of things have minds.

(3) Both kinds of dispositional concepts involved in the correlation are described in a manner which allows for degrees. The proportion of a body's capacity to perform certain causal roles corresponds to the proportion of its mind's perceptions. It would, however, be wrong to conclude that Spinoza wanted to provide a quantitative analysis of the mental. The Ethics not only lacks any reliable system of measuring the causal roles of bodies. It also suggests, looking at the rather sketchy way his mechanistic physics is exposed just after the above cited statement, that Spinoza did not even want to develop one. The correlation between bodily and mental capacities, though it could be elaborated in a more sophisticated manner, is not primarily thought of as leading to results in scientific measuring, but to provide a ground for a rational ascription of mental dispositions.

Spinoza's claim of a correlation between mental and physical capacities does not have the status of a descriptive hypothesis that can be empirically confirmed or falsified.I It explicates some kind conceptual device which he considers to be fundamental for his analysis of the mental. The resulting position is much closer to our ordinary intuitions than it appears to be at first glance. To illustrate this point, remember for a moment Thomas Nagel's

38 Cf 2p7: The order and connection of ideas is the same as the order and connection of things. Collected Works, 451

39 Collected Works, 460 
famous question What's like to be a bat?. I will however utilize it differently from the manner in which it is commonly used in the literature. ${ }^{40}$ In recent discussions of contemporary philosophy of mind this question has mainly been brought up in order to argue for the inexplicability of conscious experience from a third person perspective. Nagel himself uses it in this way. Part of the game of Nagel's thought experiment, however, lies in the fact that it makes use of a highly suggestive question we frequently raise in ordinary speech in order to appeal to the imagination of others. We often question what's like to be an $\mathrm{x}$ or a $\mathrm{y}$. It makes sense to ask what it is like to be this or that creature, though we might often lack the answer. In everyday life, we often raise similar questions in regard to other persons. We, for instance, ask what it is like to be an inhabitant of one of these regions which, for the fourth time within a few years, have been inundated. And we sometimes even appeal to others by questioning what's like to be in this or that position.

Spinoza's assumption that mental and physical capacities are correlated will of course not contribute to a solution of the problem of consciousness. (Anyway, I think the problem of consciousness in the modern sense of the word is beyond Spinoza's historical horizon, but that's another issue I will not address here.) But this correlation does help clarify another point which is of an even greater importance. There is a striking tension in our intuitions about whether or not we can really know what's like to be someone or something else. It is often assumed that we cannot know what it is like to be something or someone else "unless we put on his shoes and walk around a little bit." On the other hand, we tend to think that other entities experience certain affections more or less in the manner that we do, if we had a similar constitution and if we were in similar circumstances. We therefore presuppose that the experiences of different subjects are systematically comparable with our own experience.

Contemporary discussions in the philosophy of consciousness suggest that we have to reject one of these two intuitions. Spinoza's conceptual device, in contrast, takes them to be quite compatible. Due to the universality of the assumed correlation, we only need one single psychology for all kind of beings. On the other hand, given that the difference between our mental capacities and the capacities of other beings is a matter of degree, it can easily happen that, from a certain degree onward, the differences are so big that they go beyond our imaginative capacities to envisage what it is like to be $\mathrm{x}$ or y. This, however, is not to say that an explanation of other minds is completely impossible.

40 Nagel indirectly suggests my unorthodox reading of his example, by the justification he gives for his choice of bats instead of mice, pigeons or whales: "if one travels too far down the phylogenetic tree, people gradually shed their faith that there is experience at all " Nagel 1991, 423 (emphasis UR) 
To summarize the results of this section, Spinoza does not reduce the mental to the physical by claiming that an overall proportionate correlation between mental and physical capacities exists. Nor does he forcibly maintain the idea that all things are endowed with minds. Instead, he establishes a conceptual device which provides us with a structure that enables us to account systematically for all types of mental capacities. The assumption of a proportionate correlation between mental and physical capacities is an important corroboration of the rationalist claim that all there is and all that happens in the world is completely conceivable. It places rationalism in an ontological region that is often thought to be epistemically inaccessible, the realm of the subjective experience of other things.

\section{Conclusion: Explicable Explainers}

In this paper, I have discussed Spinoza's views on those issues which are systematically related to the question of dispositional properties; in particular to the topic of mental dispositions. Although his metaphysical views appear to be rather odd at first glance, they can be understood as expressing a very simple, rationalist expectation, that is, the idea that every thing and every phenomenon, if only analyzed carefully enough and by means of the right concepts, can be fully understood. Spinoza emphatically embraces this idea, but as I have argued, that is all he wants to say when he denies in 1p33 that "[t]hings could have been produced by God in no other way (...) than they have been produced." 41 He does not, however, reject the idea of something possibly being the case nor does he deny that dispositional properties are real.

There remains however a puzzling ambiguity. According to Spinoza's rationalism it is possible to analyze all of our notions of dispositional properties in terms of actual causal relations. On the other hand, since all finite things are causally linked to each other, a complete analysis would require so much knowledge that it seems to surpass our cognitive capacities. As finite human beings we, thus, may never be able to completely describe any property of a thing. Therefore, the complete description of dispositional concepts through concepts of actual terms is at the same time both possible and impossible. It is ontologically conceivable. But historically, it can never be achieved.

All of this, however, does not have to vex Spinoza, since his claim regarding a complete analysis of dispositional properties does not amount to an ontological denial of their reality. He can confidently accept to live and work in a provisional state of knowing. His combination of radical rationalism with common sense realism is a bet whereby he gains a lot without losing anything.

41 Collected Works, p 436 


\section{Literature}

Descartes, René. 1996. Oewures de Descartes. Ed. Charles Adam/Paul Tannery. Paris: Vrin $(=\mathrm{AT})$.

Bartuschat, Wolfgang. 1992. Spinozas Theorie des Menschen. Hamburg: Meiner.

Brandom, Robert. 1976. "Adequacy and the Individuation of Ideas in Spinoza's Ethics." Journal of the History of Philosophy 147-162.

Carriero, John. 1991. “Spinoza's Views on Necessity in Historical Perspective.” Philosophical Topics 19: 47-96.

Curley, Edwin. 1969. Spinoza's Metaphysics. Cambridge, Mass.: Harvard University Press.

Curley, Edwin and Walski, Gregory. 1991. "Spinoza’s Necessitarianism Reconsidered.” In New Essays on the Rationalis, ed. Gennaro and Huenemann, 241-262.

Della Rocca, Michael. 1996. Representation and the Mind-Body Problem in Spinoza. Oxford: Oxford University Press.

Garrett, Don. 1991. "Spinoza's Necessitarianism.” In God and Nature: Spinoza's Metaphysics, ed. Yirmiyahu Yovel.

Gueroult, Martial. 1974. Spinoza II. L'âme. Paris.

Hampe, Michael and Schnepf, Robert, eds. 2006. Ethik in geometrischer Ordnung dargestellt. Berlin: Akademie-Verlag.

Nagel, Thomas. "What Is It Like to Be a Bat?" Reprinted in: Rosenthal, David M. 1991. The Nature of Mind. New York / Oxford: Oxford University Press.

Perler, Dominik. 2006. “Das Problem des Nezessitarismus.” In Hampe/Schnepf (eds.), 5980.

Renz, Ursula. 2006. "Die Definition des menschlichen Geistes und die numerische Differenz von Subjekten (2p11-2p13s)." In Hampe/Schnepf (eds.), 101-121.

Renz, Ursula. 2007. Die Erklärbarkeit von Erfahrung. Realismus und Subjektivität in Spinozas Theorie des menschlichen Geistes. Zürich (manuscript: Habilitationsschrift).

Rousset, Bernard. 1996. Spinoza. Lecteur des Objections faites aux Méditations de Descartes et de ses Réponses. Paris: Éditions Kimé.

Ryle, Gilbert. 1949. The Concept of Mind. London: Hutchinson.

Schütt, Hans-Peter. 1985. "Spinozas Konzeption der Modalitäten." Neue Hefte für Pbilosopbie 24/25: 165-183.

Spinoza, Baruch de. 1988. The Collected Works of Spinoza. Ed. by Edwin Curley, Princeton: Princeton University Press (= Collected Works).

Spinoza, Baruch de. 1925. Opera. Ed. by Carl Gebhardt. Heidelberg: Winter (= G I-IV).

Wilson, Margaret D. 1999. Ideas and Mechanism. Essays on early modern philosophy. Princeton: Princeton University Press.

Yoshida, Kazuhiko. 2004. Vernunft und Affektivität. Untersucbungen zu Spinozas Theorie der Politik. Würzburg: Königshausen \& Neumann. 